\title{
ESTUDO DA ESPECIFICIDADE DA ISOENZIMA MB DA CREATINAQUINASE NA CIRURGIA CARDIACA COM CIRCULAÇÃO EXTRA-CORPORAL (FASES PRÉ, INTRA E PÓS OPERATÓRIA)
}

\author{
$D$ H. Bonhorst, R. Gracias, M. G. Carvalbo, M. L. Andrade, M. A. Tavares, M. F. Silva \\ Pereira, R. Bento, R. Lima, M. J. Halpern, M. Macbado Macedo
}

Serviço de Cirurgia Cárdio-Torácica dos Hospitais Civis de Lisboa. Departamento de Bioquímica da Faculdade de Ciências Médicas da Universidade Nova de Lisboa.

\section{RESUMO}

\begin{abstract}
Estudaram-se em 6 doentes com valvulopatias reumatismais, as variaçōes da actividade enzimática no plasma, durante e após a cirurgia cardíaca com circulação extra corporal, para verificar a especificidade da isoenzima MB da creatinaquinase, comparando-a com a da CK. Estudaram-se também as variações da desidrogenase láctica no mesmo período. O protocolo de colheitas escolhido, procurava dissociar as variaఢ̧̃oes enzimáticas correspondentes aos tempos anteriores à miocardiotomia, das relacionadas com a lesão cirúrgica das fibras miocardicas. Os autores verificaram existir um paralelismo evidente entre as curvas referentes à $C K$ total e à sua isoenzima MB. Esta última elevava-se mais tardiamente, apenas durante os tempos cardíacos da intervenção, atingia o máximo no final desta e voltava mais rapidamente aos valores iniciais. A CK-MB regressava aos valores basais no $3 .^{\circ}$ dia do pós-operatório e a CK-total entre o $5 .^{\circ}$ e o $70^{\circ}$ dia. Os autores concluem que a isoenzima CK-MB é um indicador fiel e pouco sujeito a erros para deteç̧ão precoce de sofrimento das fibras musculares cardíacas. Os valores da $\mathrm{LDH}$ sofreram variações mais irregulares, atribuiveis à interferência de diversos factores, mas pareceram de interesse na deteç̧ão de complicaçōes durante o pós-operatório.
\end{abstract}

A elevação da actividade de determinadas enzimas no soro após a cirurgia cardíaca foi verificada por diversos investigadores, os quais discutem o papel relativo da ventri. culotomia, lesão hepática e hemólise na sua génese.

Consideram alguns autores que os níveis elevados atingidos, muito superiores aos encontrados na restante cirurgia torácica ou abdominal, poderão representar uma resposta complexa do organismo a um bypass cárdio-pulmonar prolongado. Outros autores admitem que o factor mais importante é a lesão directa da fibra miocárdica pela agressão cirúrgica.

$\mathrm{Na}$ bibliografia consultada, o estudo da actividade enzimática limitava-se ao periodo pós-operatório. Entre as várias enzimas estudadas, publicações recentes realçam a importância da determinação da isoenzima $\mathrm{MB}$ da creatinaquinase (CK-MB) cuja origem é quase exclusivamente miocárdica (Roberts et al 1974; Wilkinson 1970; Kraft et al 1978; Tsung 1976; Mercer e Varat 1975).

No presente trabalho debruçámo-nos sobre aspectos que não encontrámos referidos na literatura: o estudo da actividade enzimática nos tempos intra-operatórios e a comprovação por este meio, da especificidade da isoenzima CK-MB em relação à fibra miocárdica.

Seguimos um protocolo que tornou possível dissociar no tempo as alterações correspondentes a traumatismo da pele, grelha costal, músculo esquelético e pericárdio, das relacionadas com lesão miocárdica, que se realizam em tempos cirúrgicos diferentes 


\section{MATERIAL E MËTODOS}

O presente estudo foi levado a efeito em 6 doentes, 3 do sexo masculino e 3 do sexo feminino, com idades compreendidas entre os 21 e os 56 anos, dos vários operados no Serviço de Cirurgia Cárdio-Torắcica dos Hospitais Civis de Lisboa, entre 7 e 29 de Junho de 1978.

A escolha recaiu sobre doentes operados por patologia valvular, não tendo havido qualquer outro critério especial de selecção. (Quadro I).

\section{QUADRO I}

Diagnóstico, tipo e durą̧ão das operaçōes nos doentes estudados

\begin{tabular}{|c|c|c|c|c|c|}
\hline $\begin{array}{l}\text { Doente } \\
\text { N.o }\end{array}$ & Sexo & $\begin{array}{l}\text { Idade } \\
\text { (anos) }\end{array}$ & Diagnóstico & $\begin{array}{l}\text { Tipo de } \\
\text { opera çăo }\end{array}$ & $\begin{array}{l}\text { Duração do } \\
\text { Bypass }\end{array}$ \\
\hline 1 & $\mathrm{~F}$ & 32 & Doença mitral & $\begin{array}{l}\text { Prótese } \\
\text { Mitral } \\
\text { Hancock }\end{array}$ & $1 \mathrm{H} .30 \mathrm{M}$. \\
\hline 2 & $\mathbf{M}$ & 37 & $\begin{array}{c}\text { Doença } \\
\text { Mitrártica }\end{array}$ & $\begin{array}{c}\text { Dupla Prótese } \\
\text { Bjork-Shyre } \\
\text { Anuloplastia } \\
\text { Tricuspida }\end{array}$ & 3 H. 27 M. \\
\hline 3 & $\mathbf{M}$ & 21 & $\begin{array}{l}\text { Insuficiência } \\
\text { mitral }\end{array}$ & $\begin{array}{l}\text { Prótese } \\
\text { Mitral } \\
\text { Hancok }\end{array}$ & $2 \mathrm{H} .30 \mathrm{M}$. \\
\hline 4 & M & 38 & $\begin{array}{l}\text { Estenose } \\
\text { Mitral }\end{array}$ & $\begin{array}{c}\text { Prótese } \\
\text { Mitral } \\
\text { Biork-Shyre }\end{array}$ & $1 \mathrm{H} .50 \mathrm{M}$. \\
\hline 5 & $\mathbf{F}$ & 51 & $\begin{array}{c}\text { Doença } \\
\text { Mitroaórtica }\end{array}$ & $\begin{array}{l}\text { Dupla Prótese } \\
\text { Bjork-Shyre }\end{array}$ & 2 H. $55 \mathrm{M}$. \\
\hline 6 & $\mathbf{F}$ & 56 & $\begin{array}{l}\text { Reestenose } \\
\text { Mitral }\end{array}$ & $\begin{array}{c}\text { Prótese } \\
\text { Mitral } \\
\text { Bjork-Shyre }\end{array}$ & 2 H. $25 \mathrm{M}$. \\
\hline
\end{tabular}


Apresentamos em seguida no QUADRO II, o protocolo elaborado em função de tempos médico-cirúrgicos pré- intra- e pós-operatórios que nos pareceram mais susceptíveis de fornecerem informações sobre as variações enzimáticas.

\section{QUADRO II}

Protocolo utilizado

Colheitas de sangue: $\left(10 \mathrm{~cm}^{3}\right)$

1. a colheita: Punção venosa na véspera

2. ${ }^{\mathrm{a}}$ colheita: Do catéter venoso antes da esternotomia

3. Colheita: Idem, após esternotomia

4. ${ }^{a}$ colheita: Sangue do átrio direito após introdução das canulas-cavas

5. colheita: Sangue do seio coronário (se possivel) cavitário

6. ${ }^{\mathrm{a}}$ colheita: Em caso de ventriculotomia direita, colheita de sangue intra-

7.a série de colheitas: Colheita de sangue venoso a cada $30 \mathrm{~mm}$ de bypass

8.a série de colheitas: a) Sangue do seio coronário (ou do átrio direito) após desclampagem da aorta

b) Sangue venoso após descanulação

9. ${ }^{a}$ série de colheitas: Punção venosa nas manhãs dos dez dias seguintes à operação.

Os métodos de colheita de sangue e os doseamentos enzimáticos foram previamente aferidos em vários outros doentes. Não se encontraram diferenças significativas entre os valores obtidos no sangue arterial e no venoso, nem entre os determinados no soro e no plasma.

Escolheu-se a via venosa e o plasma para fazer as determinaçōes, por questão de comodidade e exequibilidade técnica. A escolha do plasma foi determinada pelo facto dos doentes estarem heparinizados durante a circulação extra-corporal (C.E.C.). 1978).

Os tempos cirúrgicos foram os habituais, descritos na literatura (Ferreira et al

A colheita realizada na véspera da operação destinava-se a obter os valores basais. A $2 .^{a}$ e $3 .^{a}$ colheitas foram escolhidas para o estudo das variações enzimáticas induzidas pela incisão dos vários tecidos, antes da agressão miocárdica. A partir da $4 .^{a}$ colheita, os níveis enzimáticos deverão reflectir já destruição de células musculares cardíacas.

Após a entrada em bypass verifica-se uma hemodiluição inicial, com estabilização subsequente. Estes aspectos justificaram a periodicidade e o número de colheitas da 7. ${ }^{\mathrm{a}}$ séric, variáveis com o tempo de perfusão.

$\mathrm{Na}$ colheita 8-a pretendeu-se o sangue que reflectisse o reinício da circulação coronária, com arrastamento de substâncias provenientes de células destruídas.

Em todos os casos foi feita proteç̧ão miocárdica com soluto cardioplégico. A técnica da cardioplegia com hipotermia, utilizada nestes doentes, consistiu na injecção intraco- 
ronária de uma solução protectora, (ST. THOMAS), a $4^{\circ} \mathrm{C}$, logo após a clampagem da aorta, juntamente com arrefecimento da cavidade pericárdica com soluto de Hartman, também a $4^{\circ} \mathrm{C}$ (Hearse et al 1976; Baimbridge et al 1977).

Manteve-se o estudo da variação enzimática durante os dez primeiros dias do pós-operatório, sendo feita uma colheita diária.

Em cada colheita extraíram-se cerca de $10 \mathrm{ml}$ de sangue venoso, a que se juntava uma gota de heparina (Anti-clotb) e se centrifugava a 2500 rotações por minuto, durante 10 minutos. Aspirava-se o plasma sobrenadante que era imediatamente guardado $a+4^{\circ} \mathrm{C}$. Após intervalo que nunca excedeu 6 horas, as amostras eram transportadas para o laboratório, sendo imediatamente analizadas ou conservadas a $-20^{\circ} \mathrm{C}$. para exame ulterior.

No laboratório foram determinadas as actividades da CK-total, da sua isoenzima $\mathrm{MB}$ e ainda da desidrogenase láctica (LDH) com as seguintes técnicas*:

A-Técnica para determinação da actividade enzimática da CK. Utilizou-se o método standardizado CK-Nac activaido.

A CK existente no soro vai reagir mediante as três reaç̧ões químicas:

$\mathrm{CK}$

$$
\begin{aligned}
& 1-\text { Creatina fosfato }+\mathrm{ADP} \leftrightarrows \text { Creatina }+ \text { ATP } \\
& \text { HK } \\
& \text { 2-ATP + Glucose } \leftrightarrows \mathrm{G} 6 \mathrm{P}+\mathrm{ADP} \text {. } \\
& \text { G6PH } \\
& 3-\mathrm{G} 6 \mathrm{P}+\mathrm{NADP}^{+} \leftrightarrows \mathrm{G} 6 \mathrm{P}+\mathrm{NADPH}+\mathrm{H}_{2}
\end{aligned}
$$

Determina-se a concentração de $\mathrm{CK}$ existente no soro mediante uma reacção cinética.

As isoenzimas sendo constituídas por cargas negativas diferentes são, eluídas por tampões de imidazol-cloreto através de colunas troca-iões (D-Sephadex A 50).

A última fraç̧ão eluída é a $\mathrm{CK}-\mathrm{MB}$, fazendo-se o seu doseamento pelo método CK-Nac já referido (Mercer e Varat 1975; Maitrot et al 1975; Lum e Levy 1975; Ogunre et al 1975; Galen e Gambino 1975; Wong e Smith 1975; Hall e De Luca 1976; Roelke e Ghleyer 1978).

A técnica descrita elimina qualquer interferência de hemólise, pela presença de diadenosinopentafosfato.

$B-T e ́ c n i c a$ para determinação da actividade enzimática da $L D H$ :

$A$ actividade da LDH foi medida espectrofotometricamente pela técnica descrita por Bücker, a qual consiste na medição da velocidade de desaparecimento do $\mathrm{NADH}_{2}$ na reacção: Piruvato $+\mathrm{NADH}_{2} \stackrel{\mathrm{pH} 7,5}{\longrightarrow}$ Lactato $+\mathrm{NADH}$

$\mathrm{O} \mathrm{NADH}$ é facilmente doseável pela sua absorpção a $366 \mathrm{~nm}$ a $25^{\circ} \mathrm{C}$ (Plomteux e Tenlet 1971; Bernstein et al 1974).

\section{RESULTADOS}

Os resultados dos doseamentos da actividade enzimática nos doentes estudados vêm expressos nas figuras 1 a 6 .

Os valores absolutos referidos não são comparáveis, visto dependerem de inúmeros factores para além da extensão das lesōes miocárdicas, diferentes de doente para doente. A grande dispersão de valores obtidos leva-nos a apresentar os resultados em gráficos separados. 
Pareceu-nos de valorizar a evolução cronológica dos níveis enzimáticos durante os tempos intra- e pós-operatórios e as analogias na progressão das curvas referentes aos vários doentes.

Sobrepusémos para cada caso as curvas da CK-total e da CK-MB em escalas diferentes o que nos permitiu constatar melhor os seus paralelismos e desfazamentos, na evolução ao longo do tempo.

Verifica-se em todos os doentes um paralelismo evidente nas curvas referentes à CK e CK-MB. A partir dos valores basais iniciais, ambas mostram progressão ao longo da intervenção cirúrgica e regressão no pós-operatório. Contudo, a CK-MB inicia mais tardiamente a sua elevação, atinge o pico mais cedo, ainda no periodo intra-operatório e decresce mais rapidamente no pós-operatório (normalização no $3 .^{\circ}$ dia em todos os doentes).

As variaçōes da CK-total sāo de maior amplitude, de início mais precoce, pico mais tardio ( $1 .^{\circ}$ ou $2 .^{\circ}$ dia do pós-operatório) e regressão mais lenta aos valores basais (entre o $5 .^{\circ}$ e o $7 .^{\circ} \mathrm{dia}$ ).

Em 5 dos 6 doentes houve nova elevação tardia ligeira da CK-MB (5. ao $7 .^{\circ}$ dia).

As curvas referentes à $\mathrm{LDH}$-total mostraram uma tendência para a progressão de valores durante toda a intervenção cirúrgica e pós-operatório, com máximo mais tardio do que a $\mathrm{CK}$ foram muito irregulares e com grandes oscilaçōes.

Por não fazer parte integrante deste trabalho não nos referimos ao estudo das isoenzimas da $\mathrm{LDH}$.

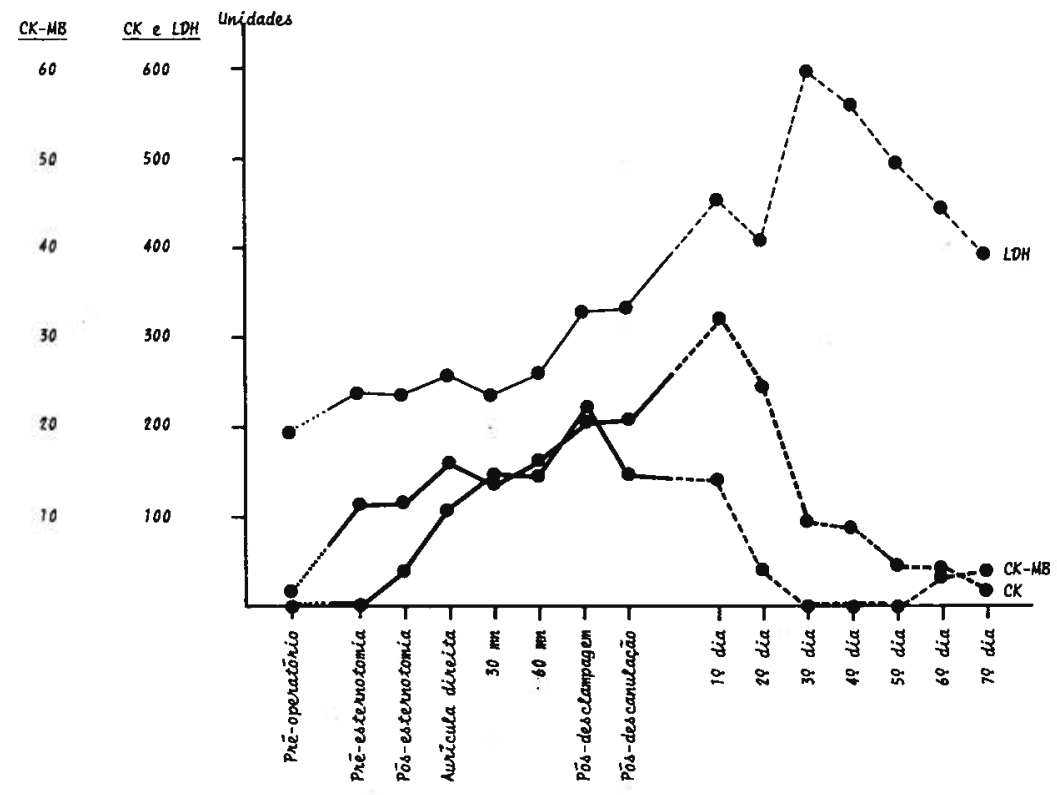

Fig. 1 -Doente N.*1-CK. CK.MB e LDH 


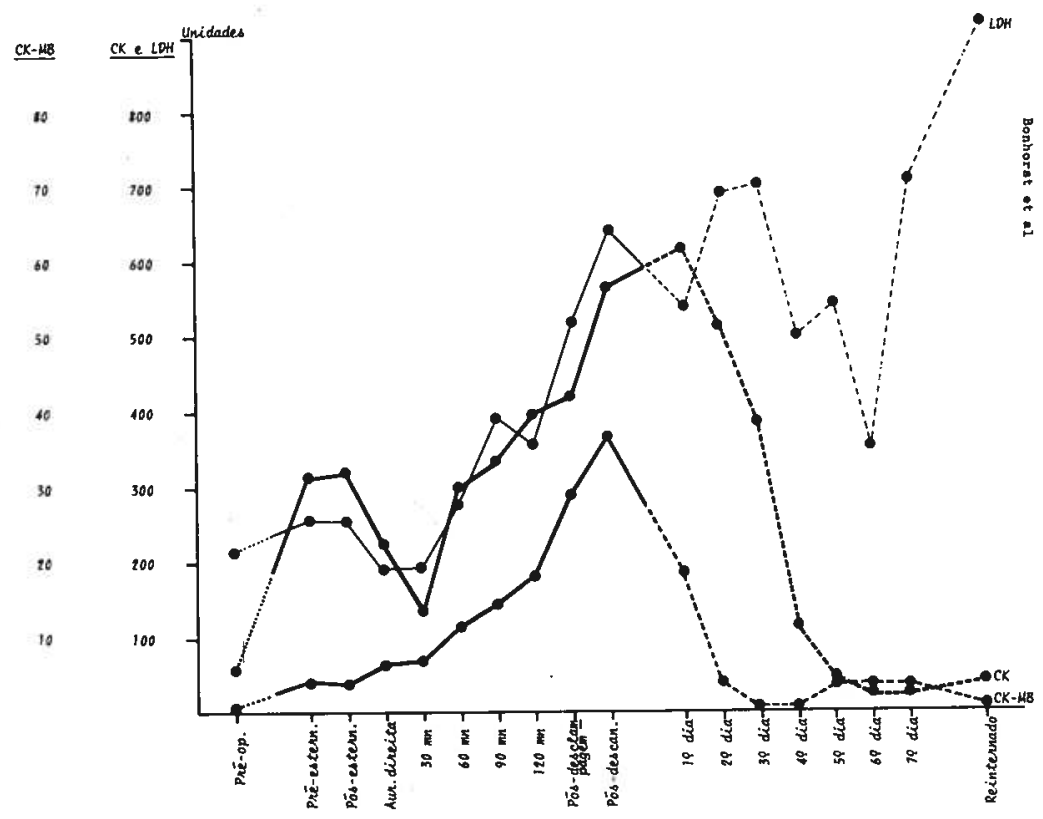

Fig. 2-Doente N. 2-CK, CK-MB e $L D H$

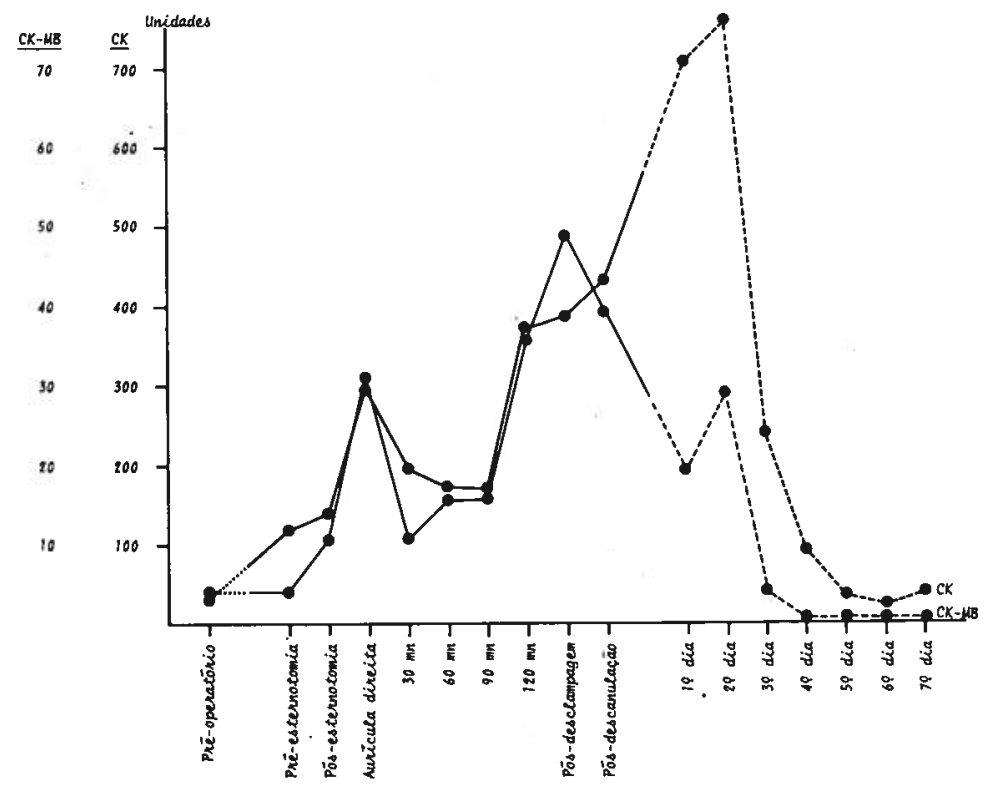

Fig. 3-Doente N." $3-C K$ e $C K \cdot M B$ 


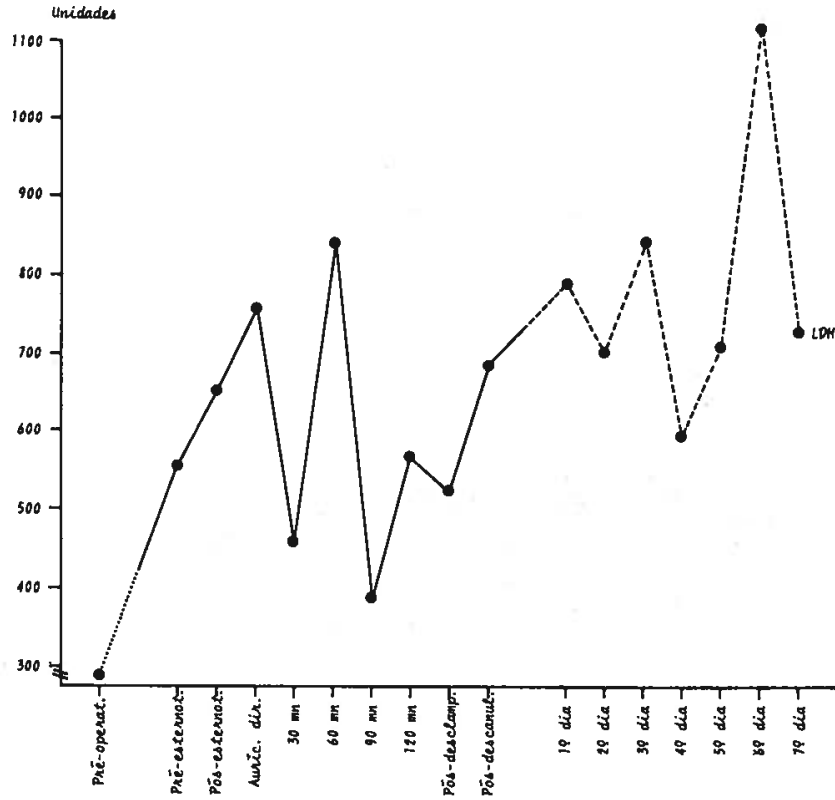

Fig. 3 a - Doente N.०3-LDH

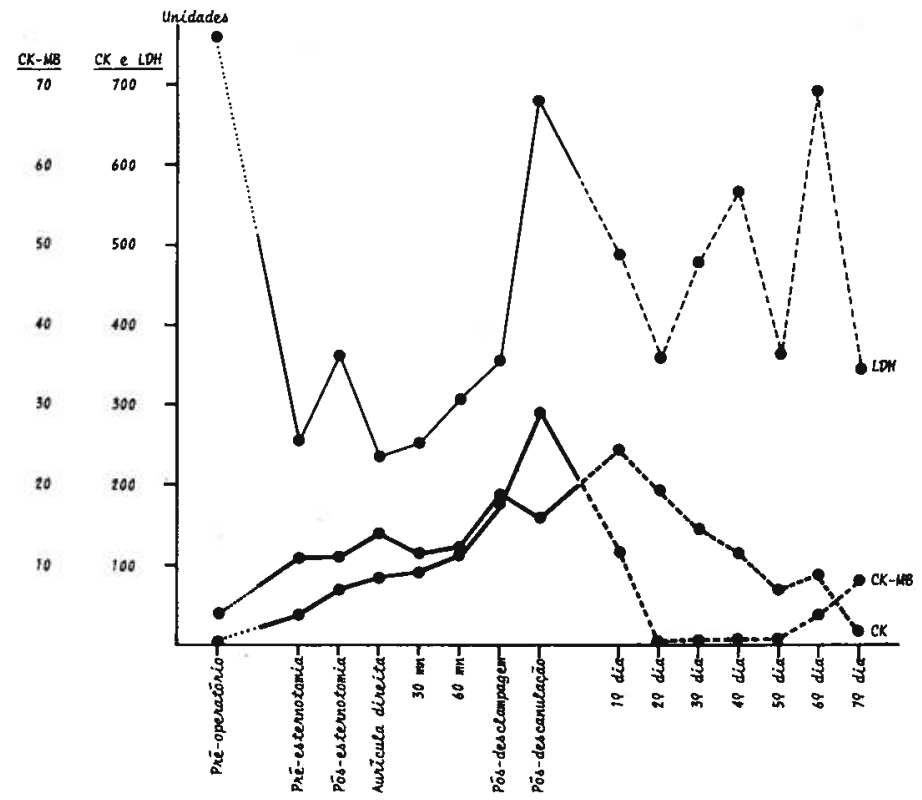

Fig. 4-Doente N. $4-C K, C K-M B$ e $L D H$ 


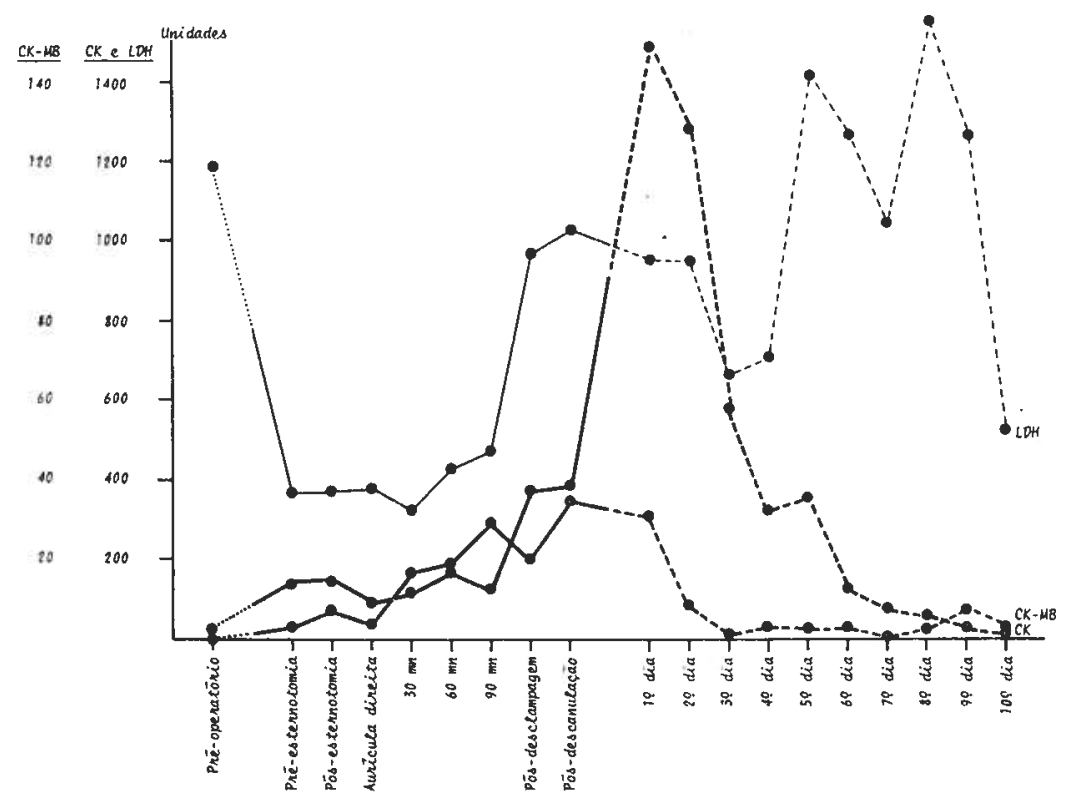

Fig. 5-Doente $N^{\circ} 5-C K, C K \cdot M B$ e $L D H$

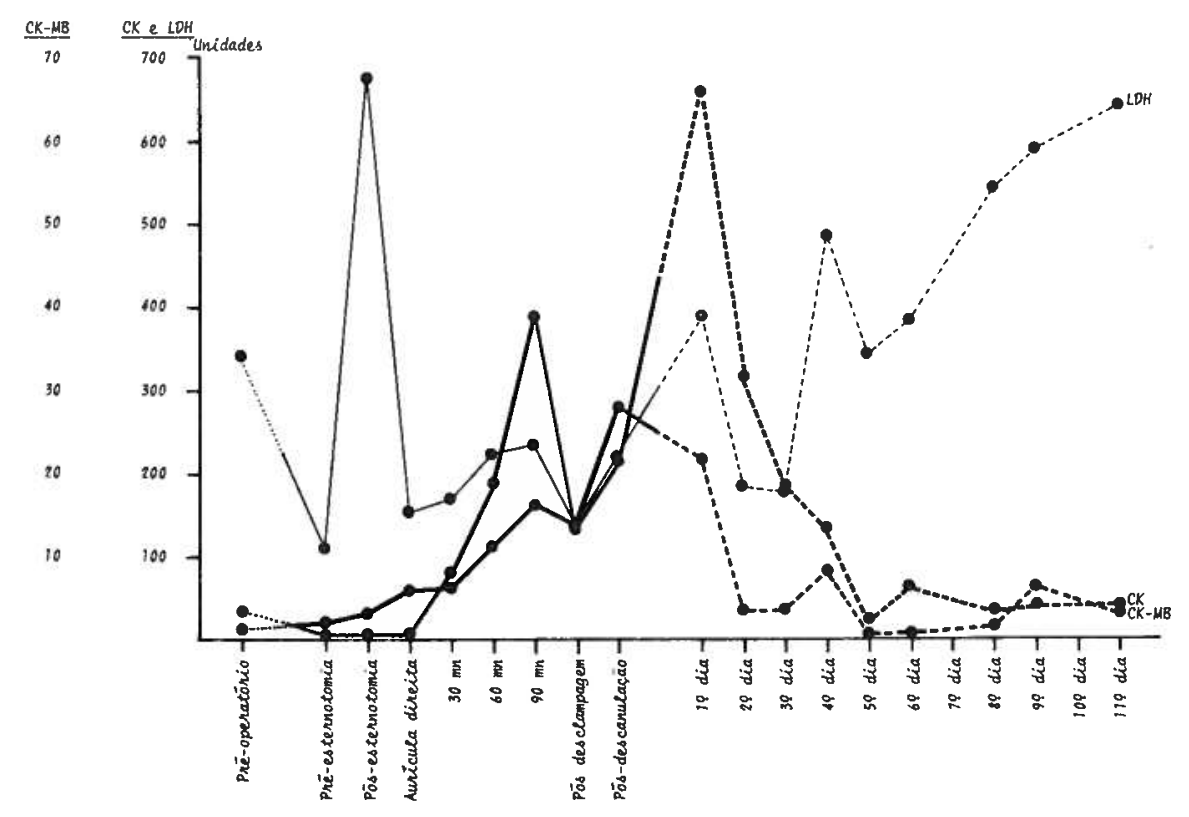

Fig. 6-Doente N." 6-CK. CK-MB E LDH 


\section{DISCUSSÃO E CONCLUSÕES}

Os níveis de actividade enzimática relacionados com lesão cardiaca, têm sido largamente estudados no enfarte do miocárdio.

A introdução do estudo de isoenzimas veio permitir maior especificidade no respeitante à detecção da lesão miocárdica. $\overline{\mathrm{E}}$ o caso das isoenzimas 1 e 2 da $\mathrm{LDH}$ e, sobretudo da isoenzima $\mathrm{MB}$ da $\mathrm{CK}$, que só recentemente se tornou possível dosear (Wolf et al 1974; Galen et al 1975; Smith et al 1976; Wolf 1976; Rossano et al 1977; Galen 1978; Kraft et al 1978; Marmer et al 1978). Técnicas laboratoriais permitem fazer esta última determinação, sem interferência do grau de hemólise, factor que muitas vezes falseia os resultados referentes a outras enzimas.

Pelo que se refere à cirurgia cardíaca, os estudos relativos às variações enzimáticas séricas, dizem respeito na sua quase totalidade, à evolução pós-operatória (Neutze et al 1974 a; Neutze et al 1974 b; Codd et al 1975; Kraft et al 1977).

No nosso estudo, analisámos também as fases pré- $e$ intra-operatórias, embora conscientes dos inúmeros factores que durante esse periodo podem afectar os níveis enzimáticos, dado que dispunhamos de um método considerado muito sensivel e específico como seja a determinação da isoenzima CK-MB (Galen e Gambino 1975; Mercer et Varat 1975).

A determinação simultânea da CK-total pareceu-nos de interesse, a fim de comparar o seu grau de especificidade miocárdica com o da respectiva isoenzima.

Procedemos também à determinação da actividade da LDH total, a qual é, contudo, muito afectada pela existência de hemólise, situação difícil, senão impossível, de evitar nas condições habituais de circulação extra-corporal.

$\mathrm{Na}$ interpretação destas variações enzimáticas, há que considerar, para além das alterações directamente relacionadas com o traumatismo cirúrgico miocárdico, a deficiente perfusão coronária, os efeitos traumáticos cirúrgicos e posturais sobre muitos tecidos, a hemodiluição realizada durante o bypass, as múltiplas transfusões, as perturbações determinadas pela anestesia, a já referida hemólise e muitos outros factores (Neutze et al 1974 a; Neutze et al 1974 b).

O tipo de variação dos valores enzimáticos que encontrámos parece confirmar a maior especificidade atribuída $\mathrm{CH}$ isoenzima CK-MB. Assim, nos tempos operatórios iniciais, que antecedem o tempo cardíaco, há já em regra elevação da CK-total, mas não ainda da CK-MB.

Podemos admitir este facto como consequência da alteração de outros tecidos que não o cardíaco.

Dos nossos estudos concluímos que, a isoenzima CK-MB é um índice muito fiel e pouco sujeito a erros, para deteç̧ão precoce de sofrimento das fibras musculares cardíacas.

Durante o tempo cardíaco e até ao final da operação, a ascenção da CK-MB é abrupta, o que sugere ser a fibra miocárdica lesada, a fonte de libertação desta isoenzima.

No tempo operatório verificou-se sempre que, após a elevação inicial da CK e CK.MB, e coincidindo com a primeira meia hora de entrada em perfusão, havia redução ou estabilização paralela da actividade destas enzimas. Este facto pareceu-nos atribuível à hemodiluiçāo provocada pela C.E.C.

A elevação tardia da CK-MB que se verificou no pós-operatório ( $5 .^{\circ}$ e $70^{\circ} \mathrm{dia}$ ) em 5 ou 6 casos poderá estar relacionada com sofrimento sub-endocárdico, descrito nestas situações (Wolf 1976) não tendo contudo ultrapassado os limites considerados normais por certos autores 
Em nenhum dos nossos casos se confirmou clínica ou electrocardiograficamente enfarte do miocárdio, situação também referida na literatura, não só em casos de cirurgia de bypass coronário (Codd et al 1975) como também na cirurgia de substituição valvular (Neutze et al 1974) e cirurgia geral (Kraft et al 1977).

As grandes variaçōes que encontrámos nos valores da $\mathrm{LDH}$-total no período intrac pós-operatório podem ser atribuídos a hemólise, hemodiluição e interferência de muitos outros factores de certo modo inevitáveis nas C.E.C.

As irregularidades na evolução dos valores da LDH no pós-operatório poderão ter aplicação prática no rastreio de complicações cardíacas e não cardiacas, quando associadas a outros dados clínicos e laboratoriais incluindo a análise das suas isoenzimas (Galen 1978).

Nos nossos casos n." 2 e n. 3 , em que houve elevação tardia acentuada da LDH. -total, a evolução clínica tornou necessário o seu reinternamento para toracotomia exploradora por suspeita clínica de loca infectada (caso 3), e, no caso 2, por suspeita de embolia pulmonar e desgarro de sutura valvular.

\section{Agradecimentos}

Agradecemos ao pessoal médico, de enfermagem e paramédico da equipa de Cirurgia Cardio-Torácica dos Hospitais Civis de Lisboa e ao pessoal da secretaria e desenhador do Departamento de Bioquimica da Faculdade de Ciências Médicas da Universidade Nova de Lisboa, a colaboração prestada, sem a qual não teria sido possível a realização do presente trabalho.

\section{SUMMARY}

In order to assess the specificity of creatinokinase isoenzyme $\mathrm{MB}$ in comparison to total CK, a study has been carried out in 6 patients with rheumatic heart valve disease, focusing the variations of enzymatic activity in the plasma during and after open heart surgery. Variations of LDH were also studied. The protocol of sampling was devised to separate enzymatic variations due to surgical lesions of several tissues, from those related to myocardial damage. The technique of determination of CK enzymatic activity was the standardized activated CK-Nac metbod. Isoenzymes were mixed by buffer of chloride-imidazole across change-ions (D-Sephadex A 50) columns. LDH activity was measured spectrophotometrically by the technique described by Bucher. The Aa. verified that there was a definite parallelism between total $\mathrm{CK}$ and its isoenzyme MB. The latter rose with some delay, and simply during cardiac manipulation. Its highest value corresponded to the end of the operation and fell rapidly to normal figures. CK-MB was back to normal on the $3 \mathrm{rd}$ postoperative day and total $\mathrm{CK}$ between the 5 th and the 7 th day.

The Aa. concluded that isoenzyme CK-MB is a very trustworthy index, subject to very few errors, to detect early damage of cardiac muscular fibers. The data concerning $\mathrm{LDH}$ showed more irregular variations, attributable to various factors, but seemed to be interesting as far as detection of postoperative complications was concerned. 


\section{BIBLIOGRAFIA}

BAIMBRIDGE MV, CHAYEN J, BITENSKY L, HEARSE DJ: Cold cardioplegia or continous coronary perfussion? Report an preliminary clinical experience as assessed cytochemically. I Thorac Cardiovase Surg 74: 900, 1977.

BERNSTEIN LH, EVERSE J, SHIENRA N, RUSSEL LJ: Detection of cardiac damage using a steady state assay for lactate dehydrogenase isoenzymes in serum. I Mal Cel Card 6: 297, 1974.

CODD JE, KAISER GC, WIENS R, BARNER HB, WILLMAN V: Myocardial injury and bypass grafting. Value of serum enzymes in diagnosis. J Thor Cardiovasc Surg 70: 489, 1975.

FERREIRA EF, OLIVEIRA MM, OLIVEIRA JMF, RODRIGUES, FD, LEAL DJC, FERREIRA: Circulação Extracorporal. Conceitos fisiopatológicos. $O$ Médico 37: 346, 1978.

GALEN RJ: O enfarte do miocárdio: orientação clínica através dos isoenzimas. Mem Med 242: 25, 1978.

GALEN R, GAMBINO SR: Creatine kinase isoenzyme MB and heart disease. Clin Chem 21: 1848,1975 .

GALEN RS, REIFFEL JA, GAMBINO SR: Diagnosis of acute myocardial infarction. Relative efficiency of serum enzyme and isoenzyme mesurements. $J A M A$ 232: 145, 1975.

HALI. N, DE LUCA M: Electrophoretic separation and quantitation of creatine kinase isozymes. Anal Biochem 76: 561, 1976.

HEARSE DJ, STEWART DA, BAIMBRIDGE MV: Celular protection during myocardial ischemia The development and characterization of 2 procedure for the induction of reversible ischemia arrest. Circulation 54: 193, 1976.

HOFFMAN JIE, BUCKBERG D: Transmural variations in myocardial perfusion. Progress in Cardiology 5: 37, 1976.

KRAFT' j, AASTRUP $H$, SCHRODER P: Diagnostic value for Acute Miocardial. Infaretion of Creatinekinase and Lactate Dehydrogenase Isoenzymes, compared with total enzymes. Acta Med Scand 203: 167, 1978.

KRAFT' J, FINK R, ROSALSKI JB: Serum enzymes and isoenzymes after surgery. Ann Clin Bioch 14: $294,1977$.

LUM G, LEVY AL: Chromatographic and' electrophoretic separation of creatine kinase isoenzymes compared. Clin Chem 21: 1601, 1975.

MAITROT B, MECHARD D, LAINE G, CRAMER J, LETAC B, JESNNET A, DAVID A: Separation et dosage de l'iso-enzyme MB de la créatine phosphokinase sérique. Ann Biol Clin 33: 385, 1975.

MARMER A, ALPAN G, KEIDAR S, GRENADIER E, PALANT A: The MB isoenzyme of creatine kinase as an indicator of severity of myocardial ischaemia. Lancet, 2: 812, 1978.

MERCER WD, VARAT MA: Detection of cardio specific creatine kinase isoenzyme in serum with normal or slightly increased total creatine kinase activity. Clin Chem 21: 1088, 1975.

NEUTZE JM, DRAKELEY MJ, BARRAT BOYER BG: Serum enzymes after cardiac surgery unde $e_{i}$ profound hypothermia with circulatory arrest and limited cardiopulmonary bypass. $A m$ Heart J 88: 553, 1974. (a)

NEUTZE JM, DRAKELEY MJ, BARRAT-BOYER BG, HUBBERT K: Serum enzymes after cardiac surgery using cardiopulmonary bypass. Am Heart $J$ 88: 425, 1974. (b)

OGUNRE EA, HEARSE DJ, SHILIINGFORD JP: Creatine kinase isoenzymes: their separation, quantitative determination and use in the assessment of acute myocardial infraction. Biochem Sor Tians 3: 425, 1975.

ROBERTS R, HENRY PD, WITTELVEEN SAG, SOBEL BE: Quantification of serum creatine phosphokinase isoenzyme activity. Am J Card 33: 650, 1974.

ROELKF, G, GHLEYER H: Isoenzymes CK-MB. J Inf Boebringer Mannbeim, 1, 1978.

ROSSANO TG, SANDERS LA, JOHNSON ES, KENNY MA, CLAYSON KJ, STRANDJERD P: Myoglobin concentration and muscle-enzyme activities in serum after myocardial infarction and cardial arrhytmia. Clin Chem 23: 868, 1977.

SMITH AE, WENG CP, OLIVER MF: Creatine kinase MB isoenzyme studies in diagnosis of myocardial infarction. Brit Heart J 38: 225. 1976. 
TSUNG SH: Creatinekinase isoenzyme patterns in human tissue obtained of surgery. Clin Chem 22: 173, 1976.

WILKINSON JH: Clinical applications of isoenzymes. Clin Chem 16: 733, 1970.

WALF PL: The diagnostic value of isoenzymes in acute M. I. Med Lab Mgt Int'l 1: 34, 1976.

WOLF PL, KEARNS T, NEUHOFF J, LAURIDSON J: Identification of CPK isoenzyme MB in myocardial infarction. Lab Med 5: 39, 1974.

WONG PC-P, SMITH AF: Comparison of 3 methods of analysis of the MB Isoenzyme of creatine kinase in serum. Clin Chem Acta 65: 99, 1975.

Pedidos de separatas: D. H. Bonborst

Serviço de Cirurgia Cardio-torácica dos Hospitais Civis de Lisboa Lisboa - Portugal 